\title{
The Characteristics of Laser Welding of a Thin Aluminum Tab and Steel Battery Case for Lithium-Ion Battery
}

\author{
Lanh Ngoc Trinh $₫$ and Dongkyoung Lee *®D \\ Department of Mechanical and Automotive Engineering, Kongju National University, Cheonan 31080, Korea; \\ trinhngoclanh199633@gmail.com \\ * Correspondence: ldkkinka@kongju.ac.kr; Tel.: +82-41-521-9260
}

Received: 20 May 2020; Accepted: 22 June 2020; Published: 24 June 2020

check for updates

\begin{abstract}
During lithium-ion battery packing, joining between battery cases and tabs is challenging for manufacturers due to dissimilar materials of the battery case and the tab, as well as their thicknesses. Laser welding, which has proven to produce a good weld with high productivity and low electrical resistance, is introduced to weld these materials. The weld was conducted with nanosecond-pulsed fiber laser and the effect of laser powers on mechanical and electrical properties as well as microstructure of the joint is investigated. The weld bead at the low laser power exhibited several blowholes on the surface, while the formation of voids including centerline and root cavities was observed through the cross-section. Moreover, the phenomenon of upward penetration (UP) was observed in all laser powers and recoil pressure which was generated by metal evaporation was supposed to cause the formation of an upward flow of the lower material. A hardness test was performed on both horizontal and vertical directions through the fusion zone. Additionally, the increase of upward penetration (UP) resulted in higher strength and lower electrical resistance of the weld.
\end{abstract}

Keywords: lithium-ion battery; laser welding; tensile strength; hardness; upward penetration; electrical resistance

\section{Introduction}

The lithium-ion battery (LIB) features several beneficial characteristics in rechargeable battery systems such as high energy density and long circle life compared with other batteries [1-4]. According to a prediction from the Bloomberg New Energy Finance (NEF) 2019 electrical vehicle outlook, the demand for LIB in the world market in various applications would rapidly raise between 2020 and 2030. The LIB has several cell designs depending on its application. The common commercial LIB cell designs are cylindrical cells, prismatic cells and pouch cells $[5,6]$.

Aluminum features high ductility, lightweight and high electrical conductivity. Aluminum has been widely applied in various industries, especially battery technology $[7,8]$. One cylindrical battery cell mainly contains an anode, a cathode, a separator and a metal case. To connect the electrodes with the metal case, a metal tab is used. However, the materials of the battery case and the tab carry difficulties for manufacturers. The battery tab is commercially made of aluminum or copper due to its excellent electrical conductivity. Meanwhile, steel is commonly chosen to be the material of the battery case. It is advantageous with high strength, long life cycle time, high hardness for preventing the penetration of the surface materials and good corrosion resistance. A nickel-plated layer on the surface of the metal battery case-widely applied by many battery manufacturers-helps to improve the joint strength and maintains low-electrical resistance between cells [9]. To achieve the desired electrical 
capacity, battery cells are connected. Some joints must be welded-especially the joint between battery case and tab. Joining these dissimilar metals is challenging for researchers and manufacturers due to differences in the physical and chemical properties of these materials. In particular, aluminum and steel have different melting temperatures which makes it hard to weld using conventional fusion welding methods. Furthermore, solubility between Fe and Al is low, which leads to the formation of a brittle intermetallic layer. The formation of intermetallic compounds (IMCs) has been proven to cause several weld defects such as microcracks and pores [10-14]. Meanwhile, IMCs imply the connection of Fe and $\mathrm{Al}$; the mentioned weld defects caused by the IMCs significantly decrease the mechanical properties of the weld. Therefore, the reduction of the formation of the IMCs is essential to improve the weld properties. A significant number of studies have been carried out to investigate the dissimilar joint with the expectation of minimizing the intermetallic layer as well as increasing joint properties. Watanabe et al. [15] have demonstrated a butt joint of an aluminum alloy and a mild steel plate using friction-stir welding. After the experiment, the conclusion was drawn that not only could the butt joint of the base materials be achieved by friction-stir welding, but also the interface between steel and aluminum showed a minimized intermetallic phase. However, the intermetallic compounds were detected at the upper part of the interface. Moreover, the maximum tensile strength of the joints was obtained at the pin offset of $0.2 \mathrm{~mm}$ to the steel side and the maximum strength equaled about $86 \%$ of that in the aluminum base material. Ultrasonic welding technology was also attempted to weld these base materials. The experiment was presented in a study of ultrasonic butt welding of aluminum and stainless-steel plate by Tsulino et al. [16]. In the study, aluminum and aluminum alloys were welded with stainless steel using a $15-\mathrm{kHz}$ powerful ultrasonic vibration source. The tensile strengths of both aluminum and aluminum alloys with stainless-steel plates were almost equal to the strength of the base aluminum. Moreover, the hardness of the materials decreased at the weld surface. Another technique has been applied to weld steel and aluminum alloy, which was studied by Qiu et al. [17]. The researcher used the resistance spot welding technique to weld aluminum alloy to cold-rolled steel and austenitic stainless steel. The maximum thickness of the reaction layer in the weld result was approximately seven micrometers. The product obtained at the reaction layer was comprised of $\mathrm{Fe}_{2} \mathrm{Al}_{5}$ and $\mathrm{FeAl}_{3}$. It was evident that the reaction layer had no influence on the weld strength. The tensile strengths of the weld increased linearly as the higher welding currents were applied. However, laser-welding technologies_that show many advantages in joining these dissimilar materials-has been widely applied in lithium-ion battery fabrication [18-24]. The laser-beam welding is characterized by low heat input and high energy density, which results in a good weld in terms of quality and productivity $[25,26]$. Moreover, laser-beam welding has shown positive results in joining dissimilar metals, such as reducing the thickness of the intermetallic layer, minimizing the formation of the pores, cracks and increasing mechanical properties of the weld [27-33]. Several studies have been conducted to investigate the effects of joining these dissimilar metals using laser-beam welding. However, the joining of the battery case and tab using low-cost laser technology has been less focused. To save the production cost of the battery, a nanosecond-pulsed fiber laser source is introduced to weld the battery case and tab during the packing process. In this study, the influence of the laser powers on welding these dissimilar metals was taken into account. In particular, the experiment aims to evaluate the possibility of welding the aluminum and steel using nanosecond laser source-as well as investigate the effect of laser powers on the microstructure, mechanical properties and electrical conductivity of the weld.

\section{Experiment}

\subsection{Materials}

For the materials to be welded, the sample of a battery case and thin tab which were made of steel and pure aluminum, respectively, were employed for the experiment. The tab was fabricated $7-\mathrm{mm}$ in width and $0.087-\mathrm{mm}$ thick. The tab was cut $4 \mathrm{~mm}$ in length for the shear strength test. 
However, for microstructure observation and other measurements, a 1-mm-long tab was used for the experiment. During the investigation, the sample for the battery case was made of steel with a thickness of $0.4 \mathrm{~mm}$. Moreover, as the commercial battery case was coated with a thin Ni layer on the surfaces, a 10- $\mu$ m-nickel layer was also coated on the sample. Before the experiment, the surfaces of both the tab and the battery case sample were treated with acetone to remove the oxide layer and dust before the experiments.

\subsection{Experiment Procedure}

The laser source used in the experiment was ytterbium pulsed fiber laser (IPG-YLPM, IPG photonics, Southbridge, Massachusetts USA). The laser source features with the maximum laser power of $20 \mathrm{~W}$, the wavelength of $1064 \mathrm{~nm}$, the laser pulse duration of $200 \mathrm{~ns}$ and a spot size of $30 \mu \mathrm{m}$. A high-quality field lens was attached below the galvo scanning head so that the laser could transport through the lens. The lens's focal length was $190 \mathrm{~mm}$. During the investigation, the experiment was conducted with different laser powers which were in a range of 10-20 W, and other parameters were kept constant. The schematic of the experimental setup is shown in Figure 1. The tab was placed over the battery case and the distance from the tab to the lens was $190 \mathrm{~mm}$.

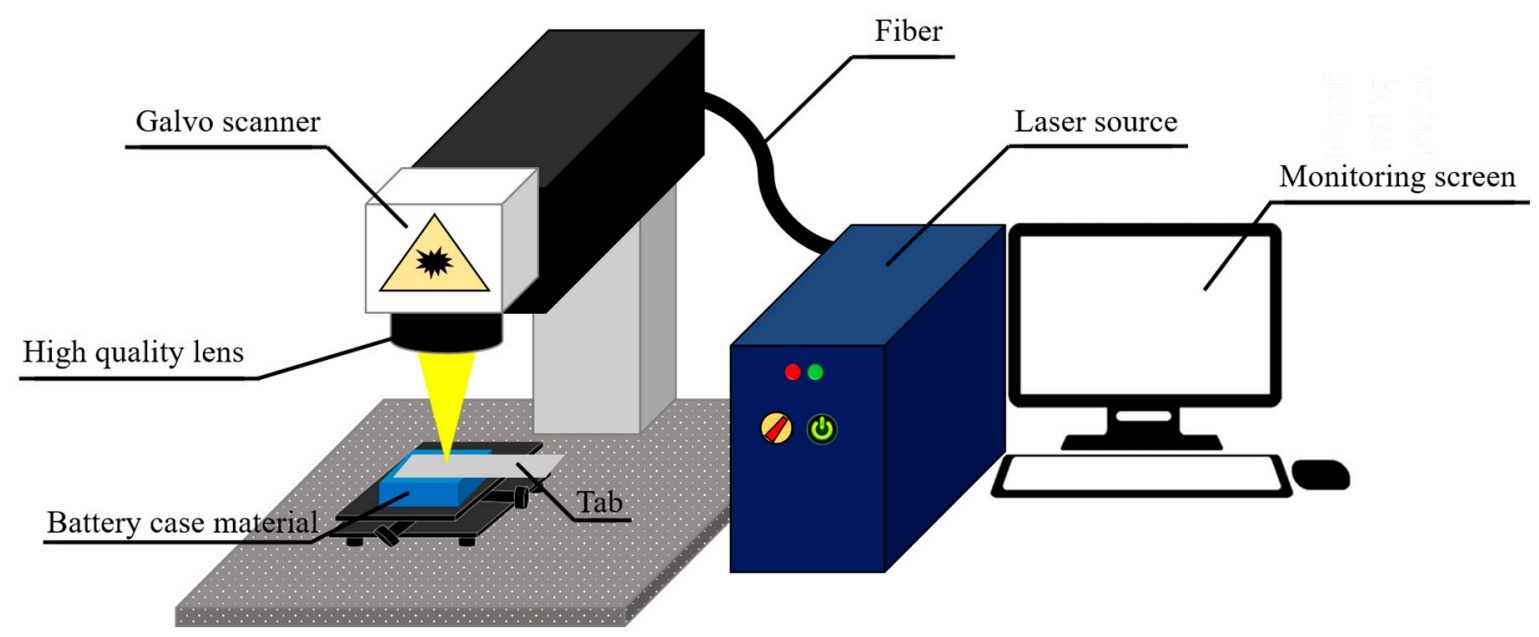

Figure 1. Experimental schematic of the battery case sample and tab welding.

The entire welding process for a typical sample lasts for about $30 \mathrm{~s}$ and the welding speed was $1 \mathrm{~m} / \mathrm{s}$. The welding process was conducted with the welding path as described in Figure 2 . As shown in the illustration, the welding path consists of a circular boundary and hatching with the parallel stripes inside the circle. First, the laser irradiated in the materials and welds the samples following a circular line. The diameter of the circle was $2.5 \mathrm{~mm}$ as shown in Figure 2a. Next, when the circle closed, the welding continuously went inside the circle and weld in straight lines shown in Figure $2 \mathrm{~b}$. The parallel stripes were created by zigzag movement. In order to create the hatching inside the circular welding line, from the ending point of the circular welding line, welding continued to create the first and smallest chord inside the circular welding line. Then, the laser shut off and jumped on the circular welding line toward the non-processing side and started to weld in the next hatching line, which was parallel with the first chord, but in the reverse direction. The distance between the two lines was kept at $0.1 \mathrm{~mm}$. The chosen welding was believed to increase the contact between the tab and the case, as well as provided the various options for analysis and observations of the weld. 

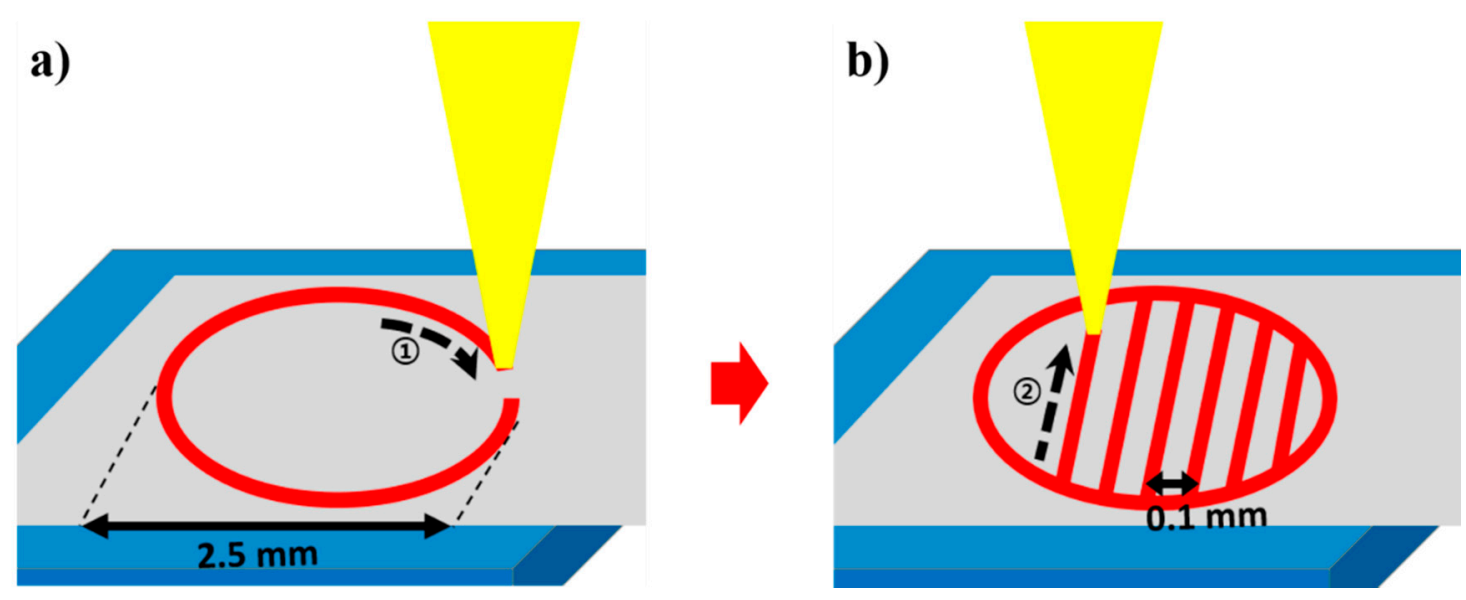

Figure 2. Illustration of the welding path. (a) Circular; (b) hatching.

\section{Result and Discussion}

\subsection{Morphology of the Weld}

The weld morphology was analyzed through the top surface, the bottom surface and the cross-section observation. First, the scanning electron microscope (SEM) was employed to observe the top and bottom surfaces of the weld. The top surface of the weld was on the tab while the bottom surface was on the battery case sample.

For the comparison, the weld appearance at the laser power of $10 \mathrm{~W}, 15 \mathrm{~W}$ and $20 \mathrm{~W}$ was chosen and shown in Figure 3. The difference on the top surface was thoroughly recognized at the circular boundary and horizontal stripes (hatching). At the laser power of $10 \mathrm{~W}$, the surface exhibited the formation of blowholes and weld metal which together appear on the welding bead. A number of blowholes were found mainly on the hatching welding lines. Meanwhile, explosive holes were detected on the circular line. The formation of these explosive holes was initiated from the formation of the blowholes which was created during the circular path welding. After this, the hatching welding path was performed. As a blowhole was created before, an accumulation of the laser energy inside the blowholes was produced [18]. This results in an increase of the recoil pressure. When the hatching welding was performed over the circular welding path, massive laser energy was produced. More material was melted, and more recoil pressure was produced. As a result, more material was pushed upwards, as well as the blowholes were open larger. Finally, the explosive holes were created. It should be noted that these explosive holes were likely found at the intersection between hatching lines and the circular welding lines where the hatching direction was departing from the circular welding line, shown in Figure $3 \mathrm{~b}$. The creation of this intersection was mentioned above. In contrast, when the laser power of $15 \mathrm{~W}$ was used, the surface revealed a significant increment of the weld metal. Moreover, the growth of the weld metal on the surface also enlarged the width of the weld bead. Thus, the gap between two weld beads of hatching lines was visible at the laser power of $10 \mathrm{~W}$, and the gap was smaller at the laser power of $15 \mathrm{~W}$. As the laser power of $20 \mathrm{~W}$ was used, the weld metal increased, as well as the entrance of the explosive holes, also expanded. The entrance of the explosive holes at this weld was about $60 \mu \mathrm{m}$ in width. Moreover, plenty of weld metal on the surface made the appearance of the surface look messy. Though the attempt of achieving a good weld surface was not aimed in the present study, it was suggested that the laser power of $15 \mathrm{~W}$ provides the fine weld surface among the laser powers. The formation of the blowholes and weld metal was suspected to be caused by the same reason. It was assumed that the vapor-induced recoil pressure initiated the formation of the blowholes and weld metal. The recoil pressure was generated by metal evaporation in keyhole mode laser welding. It begins when the laser melts the material. When the material was melted until its evaporation temperature, the melt started to vaporize. A high pressure which was produced by the metal evaporation was termed as the recoil pressure. This recoil pressure tended 
to push the melt flow away as well as accelerated the movement in the melt flow. In the present experiment, the upper material (aluminum) had low melting and evaporation temperature. Therefore, the laser could melt the material and make it vaporize quickly. The combination of the recoil pressure and the Marangoni effect made the melt flow upwards [34]. Additionally, the lower material (steel) was plated with a nickel layer since the melting point of nickel was much lower than that of the steel. This nickel layer was pre-heated during the laser beam melt the upper material; this accelerated the melting process of the nickel. Consequently, the layer was easy to vaporize. The nickel evaporation produced the recoil pressure, this pushed to the molten aluminum and creases the pores. When the pressure was high enough, the pore was opened. As a result, the blowholes were created after the cooling process as shown in Figure 3a. The blowholes were rarely found at the laser power of $15 \mathrm{~W}$ and $20 \mathrm{~W}$. This was supposedly caused by (1) the high absorption of laser energy of the nickel vapor as well as (2) the growth of the weld metal on the surface. When the higher laser power was used, it increased the energy absorption of the nickel vapor. As a result, the temperature of the nickel vapor increased. This also increased the pressure of the nickel vapor and make it successfully escape from the keyhole. Moreover, it was also assumed that the growth of weld metal made it hard to recognize the blowholes. In addition, the weld metal was generated due to the upward flow of the melt which accelerated the recoil pressure. As the nanosecond pulse laser produced the weld with a high aspect ratio, the melt in the keyhole tended to be pushed upwards along the keyhole wall under the effect of recoil pressure [35]. Then, the melt temporarily placed on the surface. After the laser shuts off, the weld metal flowed back to the keyhole. However, the solidification process of the melt took place rapidly, then weld metal was formed on the surface by solidified material. Additionally, these weld metal created a swelling surface which was demonstrated by Gao et al. [36]. The weld metal was observed increasingly at the laser power of $15 \mathrm{~W}$ and $20 \mathrm{~W}$. The increase of laser power contributed to higher laser energy absorption of the material-as well as the growth of the recoil pressure. As a result, more weld metal was produced on the surface. In other words, the increase of the laser power developed the formation of the swelling surface and reduced the number of blowholes.

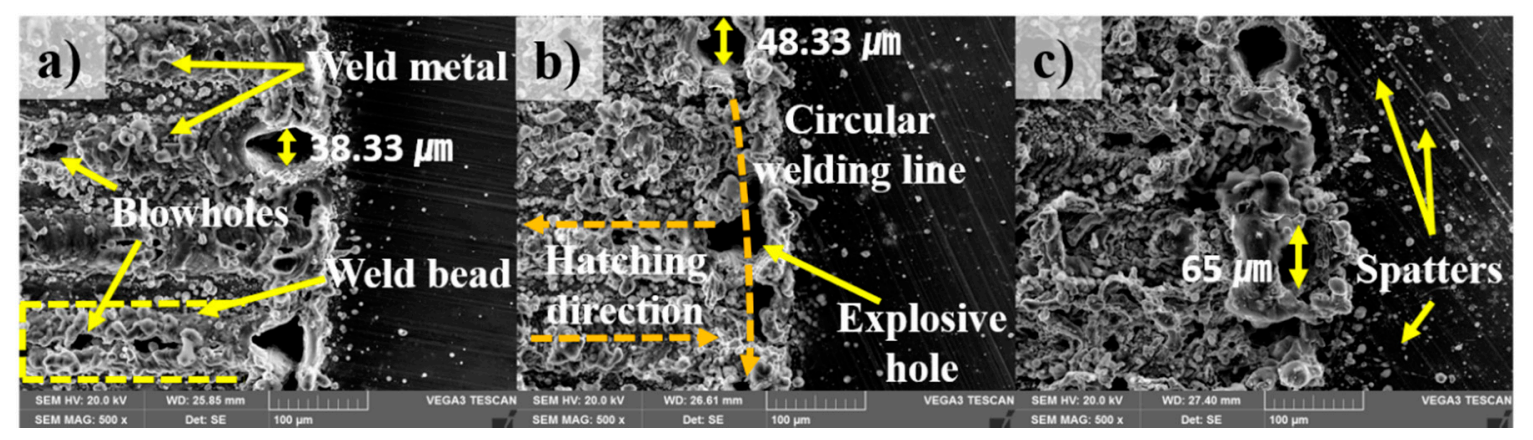

Figure 3. SEM images of the top view (a) $10 \mathrm{~W}$, (b) $15 \mathrm{~W}$ and (c) $20 \mathrm{~W}$.

In addition, spatters were also well observed on the top surface. As shown in Figure 3a, spatters were found close to the weld bead on the surface. When the weld was conducted with the laser power of $10 \mathrm{~W}$, the diameter of the spatters was around $10 \mu \mathrm{m}$. Moreover, a significant increase in the number of spatters was observed when the laser power of $15 \mathrm{~W}$ and $20 \mathrm{~W}$ were used. These spatters seemed to grow in size, especially at the laser power of $20 \mathrm{~W}$. At these laser powers, the spatters were found to locate far away from the weld bead. As mentioned above, the recoil pressure accelerated the movement to form the swelling (weld metal on the surface). However, the swelling was prevented by the surface tension. Only when the momentum of the melt could overcome the surface tension, the upper part of the swelling was ejected, and spatters were formed [37]. In other words, the surface tension considerably influenced the formation of the spatters. When higher laser powers such as $15 \mathrm{~W}$ and $20 \mathrm{~W}$ were used, the recoil pressure and the melt were produced increasingly. As a result, increasing spatters were generated. In addition, at the higher momentum, the spatters were ejected 
farther from the weld bead. In short, the laser power had a significant impact on the surface appearance including the growth of the spatters, as well as the weld metal.

The SEM observation on the bottom of the weld exhibited a significantly different appearance according to the laser power. The appearance of the bottom surface showed keyhole exits according to the welding path. These keyhole exits were assumed as the keyhole exits. It could be concluded that the full penetration of the laser irradiation occurred in the weld, especially at the laser power of $15 \mathrm{~W}$ and $20 \mathrm{~W}$ as shown in Figure 4. On the other hand, the full penetration was hardly found at the laser power of $10 \mathrm{~W}$, there were only a few keyhole exits recognized on the bottom surface. If we take a close look at the laser power of $15 \mathrm{~W}$ and $20 \mathrm{~W}$, the welding trace produced at the laser power $20 \mathrm{~W}$ was bigger than that at the laser power of $15 \mathrm{~W}$. In summary, there was a change in penetration depth between laser powers, however, full penetration could be obtained with the given laser parameters.

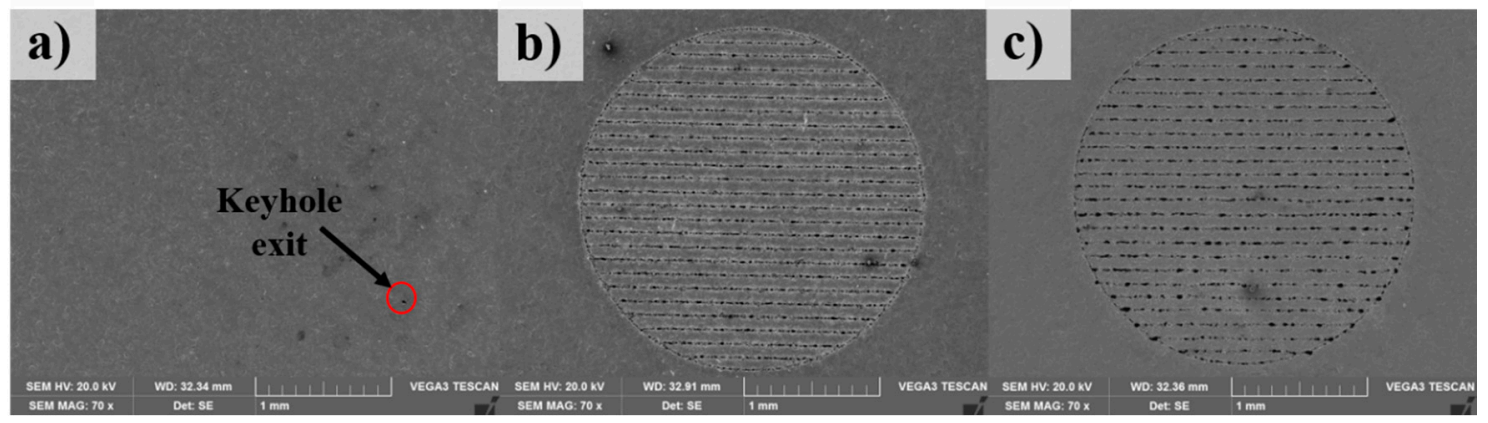

Figure 4. SEM image of the bottom view (a) $10 \mathrm{~W}$, (b) $15 \mathrm{~W}$ and (c) $20 \mathrm{~W}$.

To observe the cross-section, surface treatment was applied to the cross-section. First, the weld was cut perpendicularly with the hatching direction at the center of the welding zone. After that, the cross-section was ground and polished. The etching was applied to reveal the structure of the materials. At first, Keller's reagent ( $\left.2 \mathrm{~mL} \mathrm{HF}(48 \%)+3 \mathrm{~mL} \mathrm{HCl}+5 \mathrm{~mL} \mathrm{HNO}_{3}+190 \mathrm{~mL} \mathrm{H}_{2} \mathrm{O}\right)$ was used to etch the cross-section, but the material structure was unclearly visible. Finally, 4\% nital solution ( $4 \mathrm{~mL}$ ethanol $\mathrm{C}_{2} \mathrm{H}_{5} \mathrm{OH}+100 \mathrm{~mL}$ nitric acid $\mathrm{HNO}_{3}$ ) was employed for etching, this resulted in a clear observation of the grain boundary. The SEM observation of the cross-section is shown in Figure 5. For the analysis, the observations at the laser of $10 \mathrm{~W}, 15 \mathrm{~W}$, and $20 \mathrm{~W}$ were chosen. Overall, the cross-section of the weld was observed with a high ratio of welding depth to width (aspect ratio). Moreover, a phenomenon of the upward penetration (UP) in which the lower material was drawn into the upper material occurs at all the laser powers.

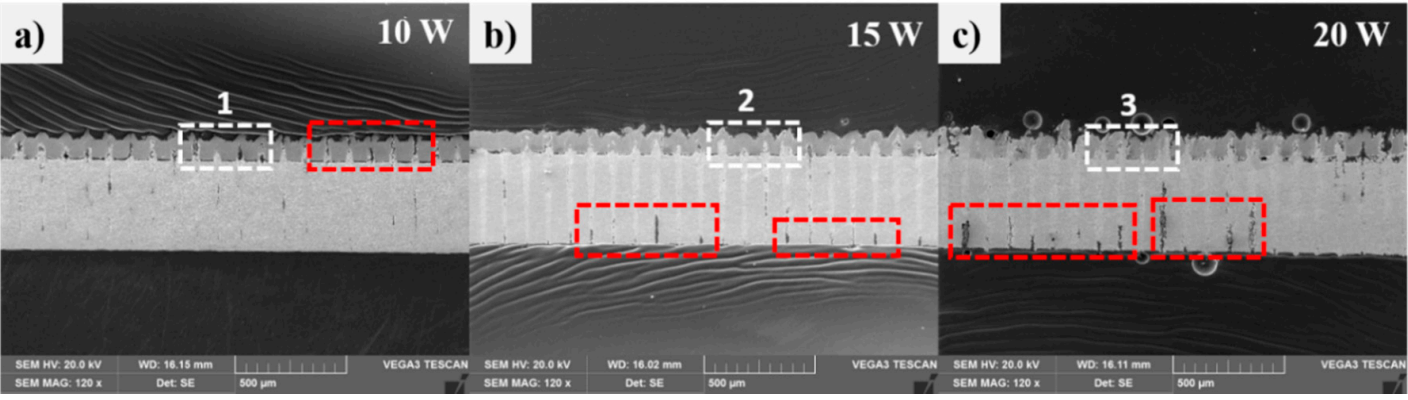

Figure 5. Cross-section view in different laser powers: (a) $10 \mathrm{~W}$, (b) $15 \mathrm{~W}$ and (c) $20 \mathrm{~W}$, respectively.

The observation on the cross-section reports several welding defects such as pores, centerline cavities, root cavities and root dropouts. The area of the red dash line indicates the location of the mentioned welding defects. At all the laser powers, centerlines cavities were detected, but they were formed at different zones according to laser powers. Particularly, at the laser power of $10 \mathrm{~W}$, blowholes and pores were found in the upper material as shown in Figure 5a. However, at the laser power of 
$15 \mathrm{~W}$ and $20 \mathrm{~W}$, the centerline cavities as well as root cavities likely located in the lower material. The centerlines cavities which were found at the laser power of $15 \mathrm{~W}$ and $20 \mathrm{~W}$ seem to be bigger than that at the laser power of $10 \mathrm{~W}$ as shown in Figure 5b,c. Moreover, a high aspect ratio was obtained at all laser powers. The full penetration of laser irradiation was clearly observed at the laser power of $15 \mathrm{~W}$ and $20 \mathrm{~W}$, as mentioned above. Moreover, it could be seen that the upper material was almost destroyed by the formation of several breaks and open cracks at the laser power of $20 \mathrm{~W}$. As the laser power of $10 \mathrm{~W}$ was used, the swelling surface appeared. In contrast, the fluctuation of the surface of the upper material was exhibited at the laser power of $15 \mathrm{~W}$. Additionally, an observation of the welding defects including centerline cavities, root cavities and root dropouts are shown in Figure 6. The loss of molten material was supposed to cause these defects. When the laser power increased, a large amount of molten material was pushed upwards. Consequently, there was a space formed at the bottom of the keyhole. Together with the rapid cooling process, space was not fully filled after the laser was shut off. As a result, the loss of molten material resulted in the formation of the cavities. As mentioned above, the formation of the blowholes and pores in the upper material at the laser power of $10 \mathrm{~W}$ was mainly due to the evaporation of the nickel-plated material. The nickel was heated up while laser irradiated on the upper material, which accelerated the melting process of the nickel. Moreover, the thin plated material made itself easy to melt and vaporize. The vaporization was trapped by the molten aluminum on top to form pores or it could escape from that molten material to form the blowholes after the cooling process. However, at the laser power of $15 \mathrm{~W}$ and $20 \mathrm{~W}$-due to the progressive formation of the UP, pores, and blowholes in the upper material-were hardly found.

Figure $7 \mathrm{a}-\mathrm{c}$ shows the magnified images of zone 1-3 of Figure 5, respectively. The regions are chosen as typical samples for the weld seam observation in this experiment. The images reveal the phenomena of the upward penetration (UP) of the lower material. Through the observation, it was clear that significant growth of the UP was observed when the laser power increased. The UP was well recognized at the laser power of $10 \mathrm{~W}$, the height of the UP recorded at this weld was around $40 \mu \mathrm{m}$. On the contrary, the weld with the laser power of $15 \mathrm{~W}$ revealed more UP which reached almost $70 \mu \mathrm{m}$ in height. Moreover, the observation also exhibited some pores and opening cracks within the upper material of the weld at the laser power of $10 \mathrm{~W}$ and $20 \mathrm{~W}$, respectively. At the laser power of $20 \mathrm{~W}$, the UP accessed over the thickness of the upper material. In addition, more opening cracks were found at this weld. In other words, pores were mainly formed within the upper material at the laser power of $10 \mathrm{~W}$. When the laser power of $15 \mathrm{~W}$ was used, an increase of the UP was observed. At the laser power of $20 \mathrm{~W}$, the fusion zone (FZ) revealed an inhomogeneous mixing of the materials. Moreover, the opening cracks were formed due to internal stress during the solidification, as shown in Figure 7c. Generally, at all the laser power, the FZ reveals the incomplete mixing of the molten aluminum and the molten steel. Together with this recognition, a swelling on the top surface was also produced progressively as the laser power increased. In addition, it was found that there was a gap between the upper and lower material at the laser power of $10 \mathrm{~W}$ and $15 \mathrm{~W}$. The formation of the pores was detected mainly at the center of the UP. In summary, when the joint was welded with higher laser powers, the UP grew significantly.

Regarding the phenomenon of UP, several studies had obtained similar results. Gabzdyl et al. [38] and his colleagues had conducted laser welding of aluminum and copper with the copper on top using nanosecond-pulsed laser. The cross-section of the weld showed a part of the lower material penetrated the upper material (copper). According to the authors, the phenomenon was caused by the characteristics of nanosecond pulse with high peak power. A similar result was demonstrated by Zuo et al. [27], he used Nd:YAG laser to weld the same thickness of aluminum and copper sheets, the phenomenon of upward convexity was obtained with copper in the upper material. As explained in the study, the difference in the thermal expansion coefficient was the major reason to cause the formation of the phenomenon. Aluminum has a higher thermal expansion coefficient than copper. Thus, aluminum expands more rapidly than the copper does and penetrates to the copper. Furthermore, Qiong Gao et al. [30] had investigated the use of pulsed-fiber lasers in the joining of dissimilar metals 
aluminum and magnesium. The welding results reported the phenomenon of the upward flow of the lower material (magnesium). The phenomenon was supposed due to the difference in vaporization temperature between the base materials as well as the mechanism of the nanosecond-pulsed fiber laser process. In summary, the formation of UP of the lower material was caused mainly by the characteristics of the upper and lower materials and the nature of nanosecond-pulsed fiber laser as explained in the above-mentioned studies. In this study, the upper and lower materials were aluminum and steel, respectively. Aluminum had a lower evaporation temperature than did steel, so the difference in the thermal behavior of the materials was not considered as the reason for the UP phenomena.
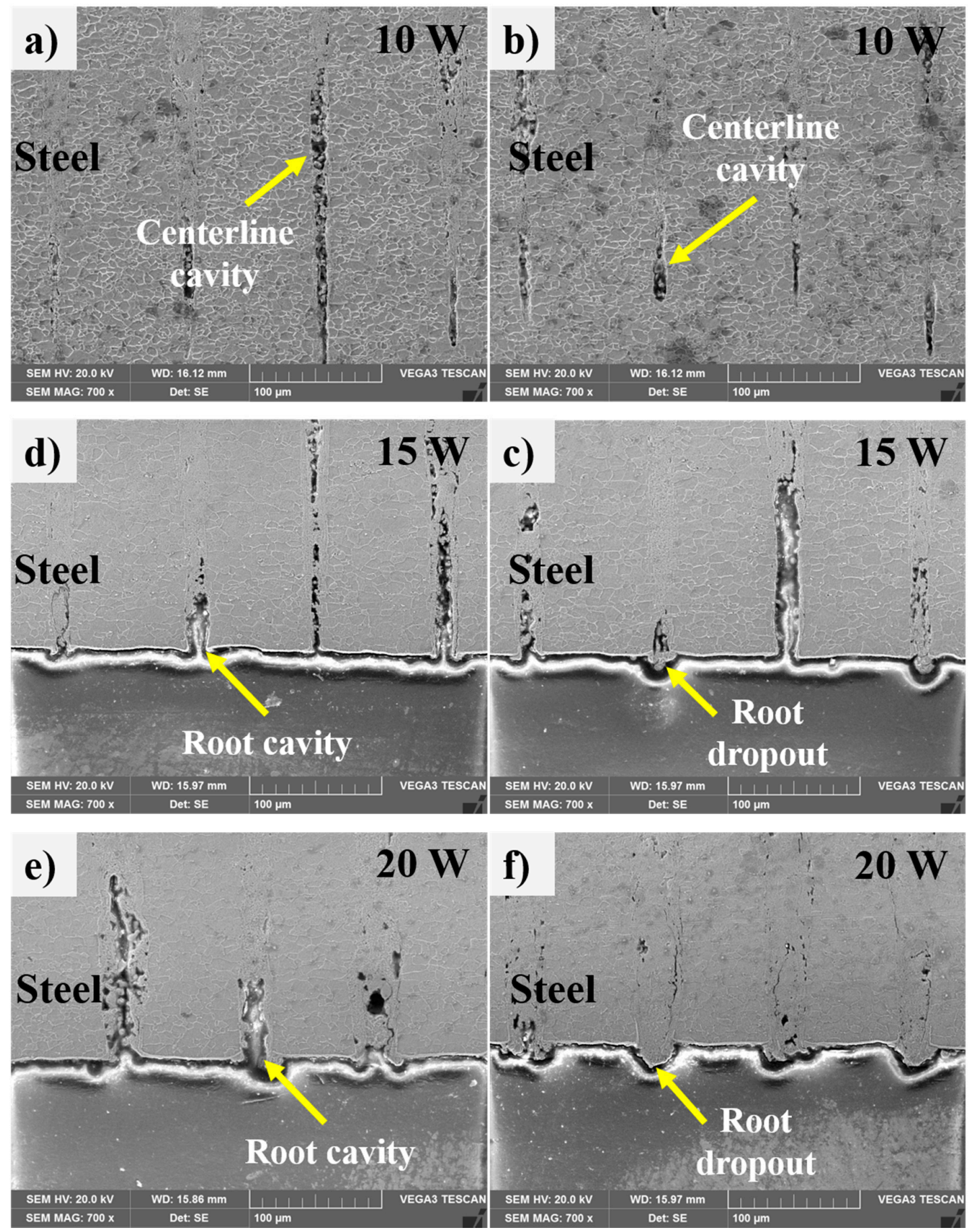

Figure 6. Centerline cavities, root cavities and root dropout, (a,b) laser power of $10 \mathrm{~W},(\mathbf{c}, \mathbf{d})$ laser power of $15 \mathrm{~W},(\mathbf{e}, \mathbf{f})$ laser power of $20 \mathrm{~W}$. 


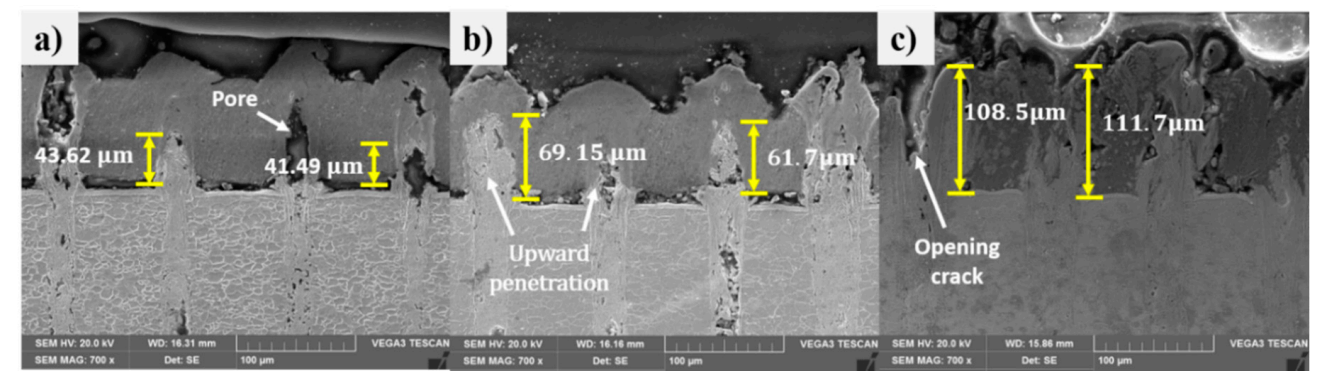

Figure 7. Magnified images of the (a) zone 1, (b) zone 2 and (c) zone 3 in Figure 5.

As we know, the density of steel (lower material) is $8.05 \mathrm{~g} / \mathrm{cm}^{3}$ which is three times higher than that of the upper material (aluminum: $2.7 \mathrm{~g} / \mathrm{cm}^{3}$ ). This implies the low possibility of mixing between these materials. Moreover, with the present welding condition, it was supposed that the UP phenomenon was also influenced by the characteristic of the nanosecond-pulsed fiber laser, especially the recoil pressure produced during the keyhole welding mode. Nanosecond-pulsed laser power owns high power density which will cause high heating and cooling rate. Based on this assumption, the formation of the UP began when the upper material was melted by the laser beam. As the welding continued, the temperature of the melt increased continuously until the vaporizing temperature. By this time, the upper part of the melt started to evaporate. The metal evaporation resulted in high pressure (recoil pressure). This pressure was the main factor that accelerated the movement of the melt. Additionally, the nanosecond-pulsed laser produced the weld with a high aspect ratio. These factors together resulted in the formation of UP as illustrated in Figure 8. Additionally, the upper material was much thinner in comparison with the lower one, which allowed the laser irradiated through it easily. In Figure 8a, the process of melting of the upper material and the flow of the melt are described; the melt was pushed upwards and to the corner due to the recoil pressure. The laser irradiation went through the upper material and started to interact with the lower material. This made the recoil pressure increased continuously since more material was melted and evaporated. As a result, the lower material was pushed upwards and flowed with the upper melt as shown in Figure 8b. By this time, the melt contains the molten materials of both the upper material and the lower material. As mentioned above, the deep and narrow keyhole produced by the nanosecond-pulsed laser forced the molten material flow parallel to the keyhole wall [39]. In addition, as aluminum and steel had low solubility, this resulted in the melt with two separate parts which were molten aluminum and molten steel. When the laser shut off, the molten material flowed downwards to refill the keyhole due to gravity as illustrated in Figure 8c. Finally, due to rapid solidification, the molten material was unable to fully fill the keyhole. In the end, the weld seam was formed as shown in Figure 8d. It was also found that the UP increased as the laser power increased.

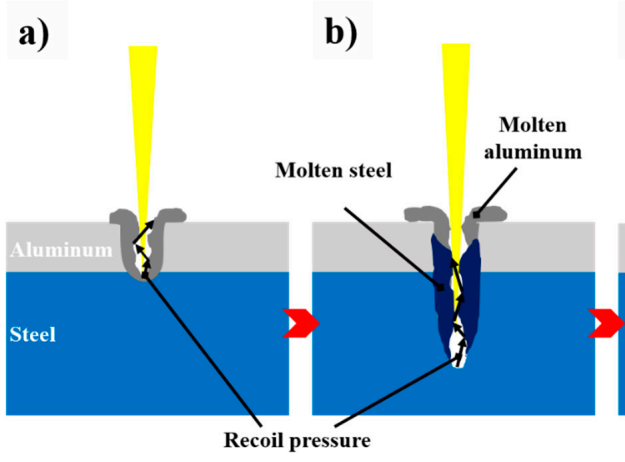

c)

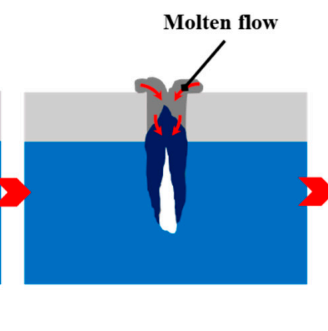

d)

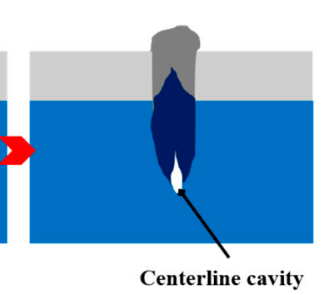

Figure 8. Illustration of the formation of "upward penetration (UP)": (a) melting process of the upper material, (b) melting process of the lower material, (c) downward flow of the molten material, (d) the cross-section after solidification. 


\subsection{Tensile Strength Test}

In the present study, the effect of laser powers on the tensile strength of the weld was focused. Therefore, the decision for the optimal tensile strength had not been designated yet. In the present experiment, the tensile strength measurement was performed with the universal testing machine (model: Shimadzu Ag-X Plus, Shimadzu Europa GmbH, Duisburg, Germany). The schematic of the test is shown in Figure 9a. The test was conducted continuously until the tab was completely detached from the battery case sample and the maximum tensile strengths were recorded. Overall, an increase of the tensile strengths of the weld with the increasing laser power was reported, as shown in Figure $9 \mathrm{~b}$. There was a slight increase in the interval from $0.47 \mathrm{MPa}$ to $0.55 \mathrm{MPa}$ between the laser power of $10 \mathrm{~W}$ and $15 \mathrm{~W}$. After that the strength of the weld increased sharply and reach the peak tensile strength of 1.12 MPa at the laser power of $20 \mathrm{~W}$. The weld with laser power of $10 \mathrm{~W}$ resulted in the lowest tensile strength among the welds. The increase in the tensile strength corresponded to the increase of UP. It is also interesting to note that at all laser powers, the failure took place at the circular welding path. Therefore, the low tensile strength of the joints was also affected by the welding path. As mentioned above, the explosive holes were found along the circular welding path, this made the tab easy to be separated in the regions during the tensile strength measurement. As a result, the welding area was still attached to the battery case sample after the tensile test, as shown in Figure 10. Moreover, in the weld with the laser power of $20 \mathrm{~W}$, a part of the tab was torn, the torn part started from a spot on the circular welding path on the circular boundary. Therefore, one could be concluded that the UP strengthened the joint.

a)

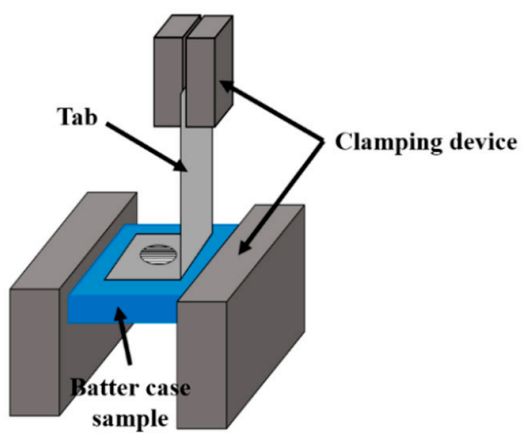

b)

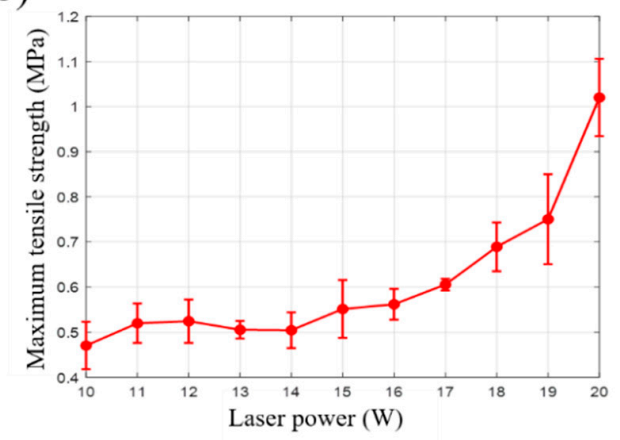

Figure 9. (a) Schematic of the tensile test; (b) tensile strength of the weld.

a)

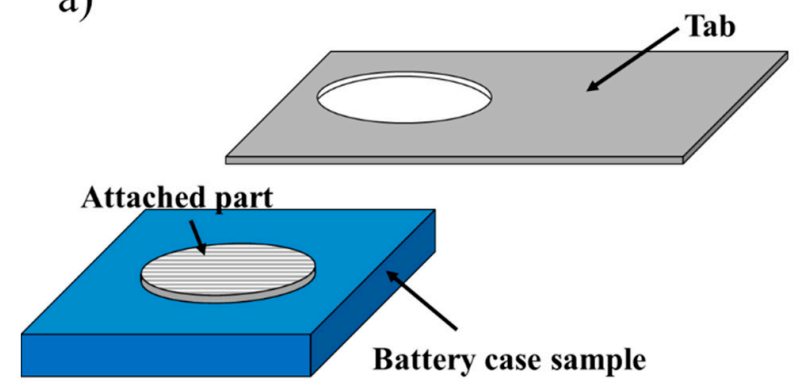

b)

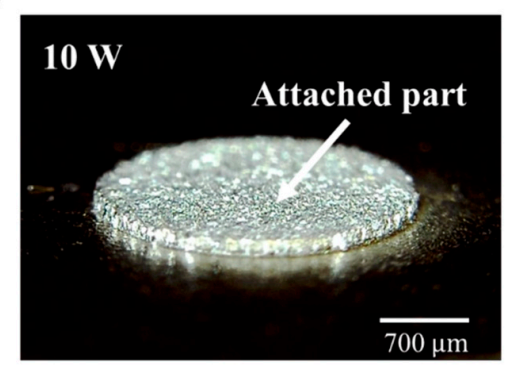

Figure 10. (a) Schematic of the attached tab after the tensile test; (b) attached tab at the laser power $10 \mathrm{~W}$.

\subsection{Hardness Test}

In this experiment, the hardness test was performed around the FZ. The Vickers hardness test was carried out in both vertical and horizontal directions. The schematic illustration for the hardness test which was performed in the vertical direction is shown in Figure 11. During the measurement, there was 
a total of 12 spots which were measured; the distance between 2 spots was $20 \mu \mathrm{m}$. The measurement was performed from the upper material to the lower material. The hardness profiles of the welds with the laser power of $10 \mathrm{~W}, 15 \mathrm{~W}$ and $20 \mathrm{~W}$ were analyzed and shown in Figure 11b). It can be seen that the hardness in the upper material increased rapidly as the distance was close to the interface between the upper and lower material. At the laser power of $10 \mathrm{~W}$, the hardness rose from $94.9 \mathrm{HV}$ to $302.1 \mathrm{HV}$ within the area. However, the hardness at the starting spot in the weld with the laser power of $20 \mathrm{~W}$ was almost double that in the weld with the laser power of $10 \mathrm{~W}$. This was due to the increase of the amount of the lower material, which was solidified at the region. The hardness distribution from the interface to the bottom of the lower material showed some changes among the laser powers. At all the laser powers, the hardness first reached the peak at the distance of $80 \mu \mathrm{m}$ from the interface, and then decreased. However, a dramatic decrease could be observed at a distance of $100 \mu \mathrm{m}$ when the laser power of $10 \mathrm{~W}$ was used. Within the distance range of 60-100 $\mu \mathrm{m}$, the hardness decreased from $320 \mathrm{HV}$ to $193 \mathrm{HV}$. In contrast, a gradual decrease in hardness was observed at the laser power of $15 \mathrm{~W}$ and $20 \mathrm{~W}$. Overall, the maximum hardness of $354.2 \mathrm{HV}$ could be observed at the laser power $20 \mathrm{~W}$. The reason for this different hardness distribution was the different penetration depth at different laser powers. Solidified material after melting was expected to have higher hardness than its base material. High penetration depth meant more material was melted and solidified. Moreover, the increase of the hardness of the material after solidified implies that the material had undergone the metallurgy process. The higher hardness corresponds to the more metallurgy that had happened. In addition, the increase of the hardness was suspected to cause the formation of the cracks and voids which negatively affect the mechanical strength of the weld.
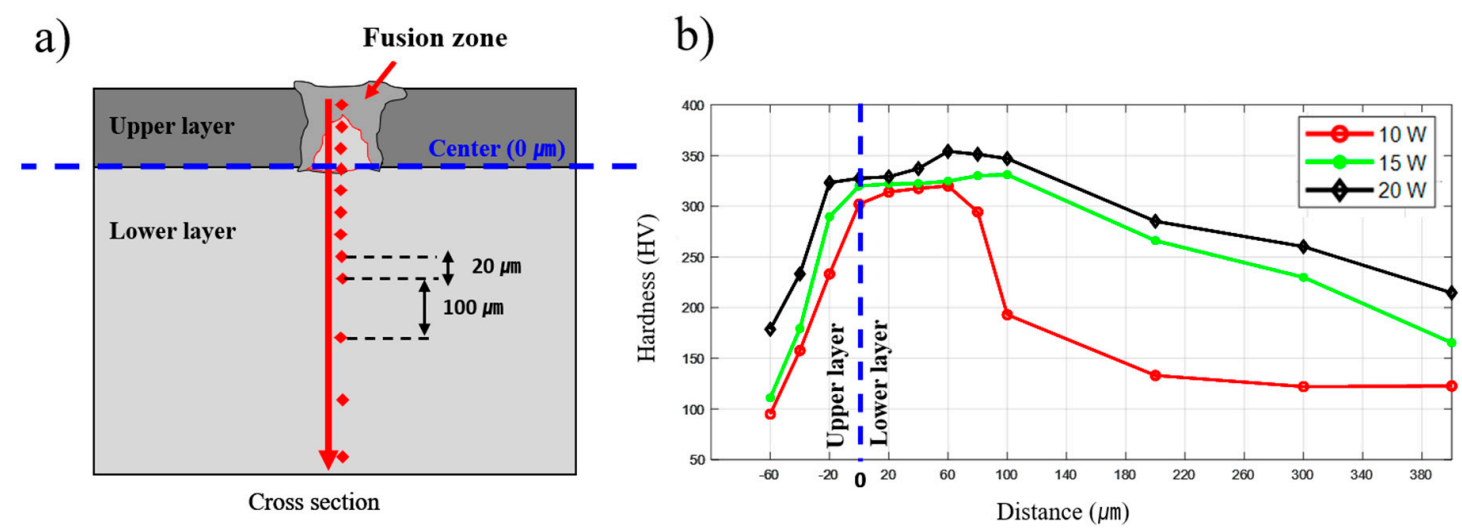

Figure 11. Hardness test on the vertical direction in the fusion zone (FZ). (a) Schematic illustration of the test; (b) hardness profile at the laser power of $10 \mathrm{~W}, 15 \mathrm{~W}$ and $20 \mathrm{~W}$.

Additionally, the Vickers hardness test was also performed across the FZ within the upper material. Figure 12 showed the illustration and the result of the hardness measurement. Generally, the hardness remained under $100 \mathrm{HV}$ outside of the FZ, but it increased sharply as the distance was close to the center of the FZ. At the laser power of $10 \mathrm{~W}$ and $15 \mathrm{~W}$, the hardness was around $40 \mathrm{HV}$ at the distance of $40-80 \mu \mathrm{m}$ from the center of the FZ. In contrast, the hardness rose from $59.5 \mathrm{HV}$ to $136.6 \mathrm{HV}$ in the region of the weld with the laser power of $20 \mathrm{~W}$. Within the distance of $40 \mu \mathrm{m}$ from the center of the FZ, the sharp increase of the hardness at the center of the FZ occurred at all the laser powers. The maximum hardness at the laser power of $20 \mathrm{~W}$ was $327.6 \mathrm{HV}$. In comparison, the laser power of $10 \mathrm{~W}$ and $15 \mathrm{~W}$ produced the maximum hardness of $314.1 \mathrm{HV}$ and $322 \mathrm{HV}$, respectively. It is clear that the increase of the UP corresponded to higher hardness at the FZ. An amount of the molten steel was pushed upwards to join in the FZ during the UP formation. The solidified steel had much higher hardness than the solidified aluminum. Therefore, the significant increase of the hardness at the FZ was observed. Moreover, at the laser power of $20 \mathrm{~W}$, an expansion of the FZ was observed. This caused the 
different hardness distribution at the distance of $40 \mu \mathrm{m}$ from the center of the FZ among the mentioned laser powers.
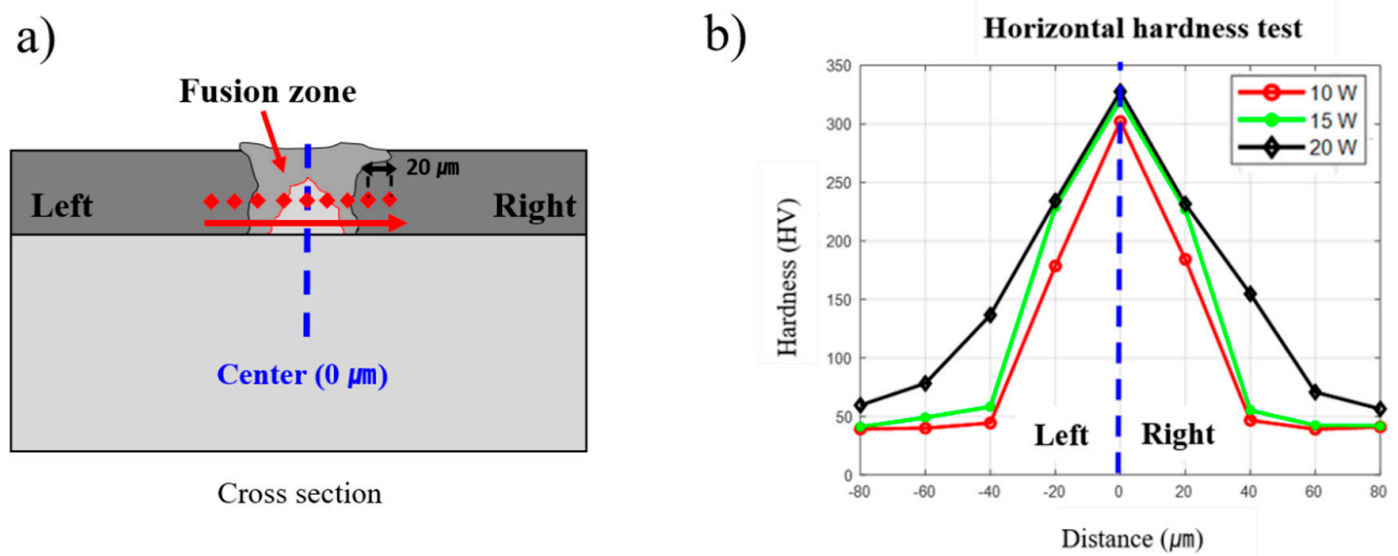

Figure 12. Hardness test on the horizontal direction in the FZ. (a) Schematic illustration of the test; (b) hardness profile at the laser power of $10 \mathrm{~W}, 15 \mathrm{~W}$ and $20 \mathrm{~W}$.

\subsection{Electrical Conductivity}

Figure 13 shows the electrical resistance of the weld in the function of the laser power. A measurement of electrical resistance was conducted following the 4-wire method, the principle of the measurement method was explained in [40]. Overall, the resistance was obtained in the interval from 0.31 to $0.46 \mathrm{~m} \Omega$ and the lowest resistance was obtained at the laser power of $20 \mathrm{~W}$. However, the fluctuation of the electrical resistance profile was reported. This fluctuation was caused by the various forms of defects in the weld, especially at the interface of the upper and lower material. As the laser power increased, a slight decrease in resistance was seen. Moreover, the decrease of the electrical resistance correlated to the amount of UP. As mentioned before, the increase of the laser power resulted in more amount of the UP as well as higher strength of the weld. Moreover, lower electrical resistances could be obtained at higher laser powers. The result could be explained through the increment of the UP which relatively increased the contact area. As more UP was formed, the contact area between the battery case and the tab increased. Moreover, the reduction of the number of pores at the interface between the upper and lower material also improved the electrical conductivity of the weld. However, the variation of the resistance was also reported in the graph. This variation may have been caused by the formation of welding defects in the weld. The number of defects formed in the weld varies, which resulted in the fluctuation of the electrical resistance when the laser power increased.

a)

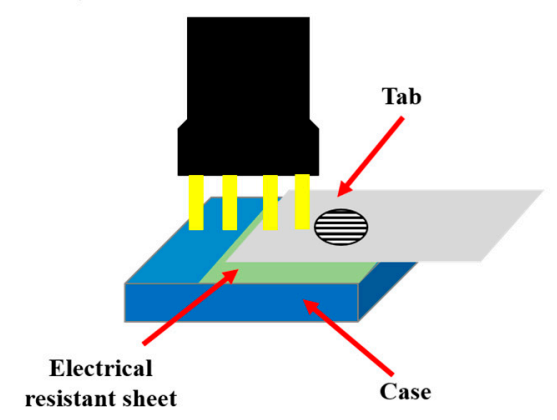

b)

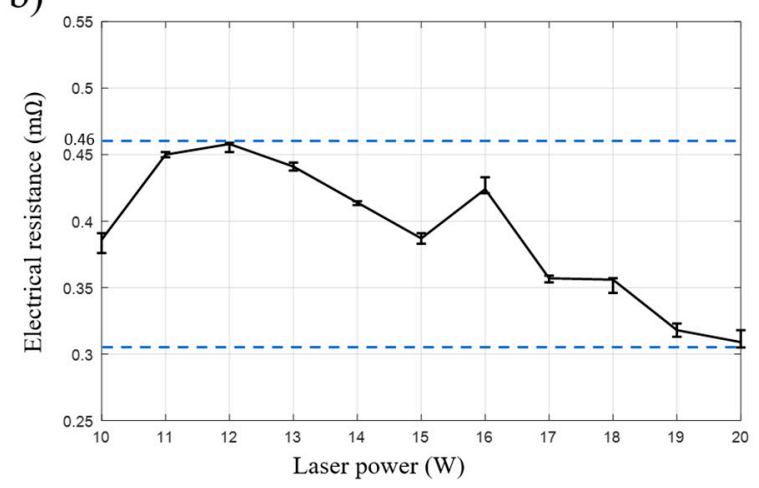

Figure 13. (a) Four-wire method measurement; (b) electrical resistance of the welds. 


\section{Conclusions}

The improvement in welding of battery case and tab in battery packing is necessary due to the disadvantages of the conventional methods. Thus, the advanced welding technology must not only overcome the problem of fusion welding for dissimilar metals, but also produce low electrical resistance joint. Laser welding which is the non-contact process helps the manufacturers to have a flexible welding schematic. Additionally, this welding technique is considered as one of the best solutions for dissimilar welding. After the investigation, several findings were recognized as follows:

- In the present experiment, the battery case and the tab are successfully welded using a cost-effective laser welding technology.

- The laser power significantly affects the morphology of the weld. Spatter and weld metal are produced increasingly as the laser power increases. Blowholes are formed on the weld surface when the weld is performed with low laser power.

- The phenomenon of upward penetration (UP) of the lower material is obtained, the recoil pressure, the characteristics of nanosecond laser and the thickness of the tab are supposed to be the major reasons causing the UP formation.

- The explosive holes on the circular welding path make the tab easy to be detached from the battery case easily during the tensile strength test. This results in the low tensile strength of the weld. The electrical resistance decreases within a range as the laser power increases.

One of the findings, upward penetration (UP), in the present study make the study unique to the previous studies. This is also considered to contribute an interesting research topic related to the technology. Through the drawbacks of the present experiment, future studies should focus on improving the joining strength as well as reducing the formation of the welding defects. In addition, further study will aim to investigate the influence of laser parameters and material properties on the UP formation.

Author Contributions: D.L. and L.N.T. conceived and designed the experiments; D.L. and L.N.T. performed the experiments; D.L. and L.N.T. analyzed the data; D.L. and L.N.T. contributed reagents/materials/analysis tools; D.L. and L.N.T. wrote the paper. All authors have read and agreed to the published version of the manuscript.

Funding: The research described herein was sponsored by the National Research Foundation of Korea (NRF) grant funded by the Korean government (MSIP; Ministry of Science, ICT \& Future Planning) (No. 2019R1A2C1089644).

Conflicts of Interest: The authors declare no conflict of interest. The opinions expressed in this study are those of the authors and do not necessarily reflect the views of the sponsors.

\section{References}

1. Yermukhambetova, A.; Tan, C.; Daemi, S.R.; Bakenov, Z.; Darr, J.A.; Brett, D.J.; Shearing, P.R. Exploring 3D microstructural evolution in Li-Sulfur battery electrodes using in-situ X-ray tomography. Sci. Rep. 2016, 6, 1-9. [CrossRef] [PubMed]

2. Kim, T.H.; Park, J.S.; Chang, S.K.; Choi, S.; Ryu, J.H.; Song, H.K. The current move of lithium ion batteries towards the next phase. Adv. Energy Mater. 2012, 2, 860-872. [CrossRef]

3. Yoshio, M.; Ralph, J.B.; Akiya, K. Lithium-Ion Batteries; Springer: New York, NY, USA, 2009.

4. Aifantis, K.E.; Hackney, S.A.; Kumar, R.V. High Energy Density Lithium Batteries: Materials, Engineering, Applications; John Wiley \& Sons: Hoboken, NJ, USA, 2010.

5. Armand, M.; Tarascon, J.M. Building better batteries. Nature 2008, 451, 652-657. [CrossRef] [PubMed]

6. Dunn, B.; Kamath, H.; Tarascon, J.M. Electrical energy storage for the grid: A battery of choices. Science 2011, 334, 928-935. [CrossRef] [PubMed]

7. Stojanovic, B.; Bukvic, M.; Epler, I. Application of Aluminum and Aluminum Alloys in Engineering. Appl. Eng. Lett. 2018, 3, 52-62. [CrossRef]

8. Hamon, Y.; Brousse, T.; Jousse, F.; Topart, P.; Buvat, P.; Schleich, D.M. Aluminum negative electrode in lithium ion batteries. J. Power Sources 2001, 97-98, 185-187. [CrossRef]

9. Steinmeier, D. Resistance Welding-Battery Pack Connections. MicroJoining Solut. 2008, 4-5. 
10. Qiu, R.; Iwamoto, C.; Satonaka, S. The influence of reaction layer on the strength of aluminum/steel joint welded by resistance spot welding. Mater. Charact. 2009, 60, 156-159. [CrossRef]

11. Bozzi, S.; Helbert-Etter, A.L.; Baudin, T.; Criqui, B.; Kerbiguet, J.G. Intermetallic compounds in Al 6016/IF-steel friction stir spot welds. Mater. Sci. Eng. A 2010, 527, 4505-4509. [CrossRef]

12. Ghosh, M.; Chatterjee, S.; Mishra, B. The effect of intermetallics on the strength properties of diffusion bonds formed between Ti-5.5Al-2.4V and 304 stainless steel. Mater. Sci. Eng. A 2003, 363, 268-274. [CrossRef]

13. Kouadri-David, A. Study of metallurgic and mechanical properties of laser welded heterogeneous joints between DP600 galvanised steel and aluminium 6082. Mater. Des. 2014, 54, 184-195. [CrossRef]

14. Springer, H.; Kostka, A.; Dos Santos, J.F.; Raabe, D. Influence of intermetallic phases and Kirkendall-porosity on the mechanical properties of joints between steel and aluminium alloys. Mater. Sci. Eng. A 2011, 528, 4630-4642. [CrossRef]

15. Watanabe, T.; Takayama, H.; Yanagisawa, A. Joining of aluminum alloy to steel by friction stir welding. J. Mater. Process. Technol. 2006, 178, 342-349. [CrossRef]

16. Tsujino, J.; Hidai, K.; Hasegawa, A.; Kanai, R.; Matsuura, H.; Matsushima, K.; Ueoka, T. Ultrasonic butt welding of aluminum, aluminum alloy and stainless steel plate specimens. Ultrasonics 2002, 40, 371-374. [CrossRef]

17. Qiu, R.; Iwamoto, C.; Satonaka, S. Interfacial microstructure and strength of steel/aluminum alloy joints welded by resistance spot welding with cover plate. J. Mater. Process. Technol. 2009, 209, 4186-4193. [CrossRef]

18. Lee, D.; Patwa, R.; Herfurth, H.; Mazumder, J. Computational and experimental studies of laser cutting of the current collectors for lithium-ion batteries. J. Power Sources 2012, 210, 327-338. [CrossRef]

19. Lee, D.; Mazumder, J. Dataset demonstrating effects of momentum transfer on sizing of current collector for lithium-ion batteries during laser cutting. Data Br. 2018, 17, 6-14. [CrossRef]

20. Lee, D.; Patwa, R.; Herfurth, H.; Mazumder, J. Parameter optimization for high speed remote laser cutting of electrodes for lithium-ion batteries. J. Laser Appl. 2016, 28, 022006. [CrossRef]

21. Lee, D. Investigation of physical phenomena and cutting efficiency for laser cutting on anode for Li-Ion batteries. Appl. Sci. 2018, 8, 266. [CrossRef]

22. Lee, D.; Ahn, S. Investigation of laser cutting width of $\mathrm{LiCoO} 2$ coated aluminum for lithium-ion batteries. Appl. Sci. 2017, 7, 914. [CrossRef]

23. Lee, D.; Patwa, R.; Herfurth, H.; Mazumder, J. Three dimensional simulation of high speed remote laser cutting of cathode for lithium-ion batteries. J. Laser Appl. 2016, 28, 032010. [CrossRef]

24. Lee, D.; Oh, B.; Suk, J. The effect of compactness on laser cutting of cathode for Lithium-Ion Batteries using continuous fiber laser. Appl. Sci. 2019, 9, 205. [CrossRef]

25. Frewin, M.R.; Scott, D.A. Finite element model of pulsed laser welding. Weld. J. (New York, USA) $1999,78$.

26. Blackburn, J. Laser Welding of Metals for Aerospace and Other Applications; Woodhead Publishing Limited: Cambridge, UK, 2012.

27. Zuo, D.; Hu, S.; Shen, J.; Xue, Z. Intermediate layer characterization and fracture behavior of laser-welded copper/aluminum metal joints. Mater. Des. 2014, 58, 357-362. [CrossRef]

28. Yan, S.; Hong, Z.; Watanabe, T.; Jingguo, T. CW/PW dual-beam YAG laser welding of steel/aluminum alloy sheets. Opt. Lasers Eng. 2010, 48, 732-736. [CrossRef]

29. Nishimoto, K.; Fujii, H.; Katayama, S. Laser pressure welding of Al alloy and low C steel. Sci. Technol. Weld. Join. 2006, 11, 224-231. [CrossRef]

30. Gao, Q.; Meco, S.; Wang, K.; Zhou, Q.; Guo, S.; Ganguly, S. Investigation of latest generation pulsed fiber laser in dissimilar joining of $\mathrm{Al}$ and Mg alloys. Chin. Opt. Lett. 2018, 16, 061401.

31. Jin, Y.; Li, Y.; Zhang, H. Microstructure and mechanical properties of pulsed laser welded Al/steel dissimilar joint. Trans. Nonferrous Met. Soc. China 2016, 26, 994-1002.

32. Lee, D. Experimental Investigation of Laser Spot Welding of Ni and Au-Sn-Ni Alloy. J. Weld. Join. 2017, 35, 1-5. [CrossRef]

33. Weigl, M.; Albert, F.; Schmidt, M. Enhancing the ductility of laser-welde copper-aluminum connections by using adapted filler materia. Phys. Procedia 2011, 12, 335-341. [CrossRef]

34. Zhou, J.; Tsai, H.L.; Lehnhoff, T.F. Investigation of transport phenomena and defect formation in pulsed laser keyhole welding of zinc-coated steels. J. Phys. D Appl. Phys. 2006, 39, 5338-5355. [CrossRef] 
35. Lee, J.Y.; Ko, S.H.; Farson, D.F.; Yoo, C.D. Mechanism of keyhole formation and stability in stationary laser welding. J. Phys. D Appl. Phys. 2002, 35, 1570-1576. [CrossRef]

36. Gao, M.; Kawahito, Y.; Kajii, S. Observation and understanding in laser welding of pure titanium at subatmospheric pressure. Opt. Express 2017, 25, 13539. [CrossRef] [PubMed]

37. Wu, D.; Hua, X.; Li, F.; Huang, L. Understanding of spatter formation in fiber laser welding of 5083 aluminum alloy. Int. J. Heat Mass Transf. 2017, 113, 730-740. [CrossRef]

38. Gabzdyl, J.; Capostagno, D. Joining Dissimilar Materials with Pulsed Nanosecond Fiber Lasers. Laser Tech. J. 2017, 14, 38-41. [CrossRef]

39. Pang, S.; Chen, L.; Zhou, J.; Yin, Y.; Chen, T. A three-dimensional sharp interface model for self-consistent keyhole and weld pool dynamics in deep penetration laser welding. J. Phys. D Appl. Phys. 2011, 44, 025301. [CrossRef]

40. Tillmann, W.; Sievers, N.; Henning, T.; Jakimenko, D. FEM study of analyzing the electrical resistance of brazed joint by the 4-wire technique for quality assurance. Meas. J. Int. Meas. Confed. 2017, 104, 43-49. [CrossRef]

(C) 2020 by the authors. Licensee MDPI, Basel, Switzerland. This article is an open access article distributed under the terms and conditions of the Creative Commons Attribution (CC BY) license (http://creativecommons.org/licenses/by/4.0/). 